\title{
TOPSIS Yöntemi ile Finansal Performans Değerlendirmesi: XUTEK Üzerinde Bir Uygulama
}

\author{
Çağatay ORÇUN* \\ B. Selman EREN**
}

\section{$\ddot{O Z Z E T}$}

Bu çalışmada, Borsa Istanbul'da (BIST) işlem gören teknoloji şirketlerinin mali performanslart TOPSIS (Technique for Order Preference by Similarity to Ideal Solution) yöntemi kullanılarak analiz edilmiştir. Çalışmada ilk olarak kullanılacak finansal oranlar belirlenmiş ve bu oranlar her şirket için ayrı ayrı hesaplanmıştır. Gerçekleştirilen analiz sonucunda 2010-2015 yılları arasında performans açısından en başarılı şirketler sirastyla, ASELS, LINK, ARMDA, LINK, INDES ve DGATE şeklinde gerçekleşmiştir. Ayrica, şirketlerin ilgili dönemlere yönelik finansal performanslar siralamalart ile borsa getiri siralamaları da analiz edilmiş ve herhangi anlamlı bir ilişki tespit edilememiştir.

Anahtar Kelimeler: XUTEK, Performans analizi, TOPSIS yöntemi.

JEL Sinıflandırması: G11, L25.

Financial Performance Evaluation with TOPSIS Method: An Application on XUTEK ABSTRACT

In this study, financial performances of technology companies traded in Stock Exchange Istanbul (BIST) were analyzed using TOPSIS (Technique for Order Preference by Ideal Solution) method. First, financial ratios were determined in the study and these ratios were calculated separately for each company. As a result of the analysis, the most successful companies in terms of performance between 2010-2015 were ASELS, LINK, ARMDA, LINK, INDES and DGATE respectively. In addition, the rankings of financial performances of the companies for the related periods and the stock return rankings were also analyzed and no meaningful relationship was found.

Keywords: XUTEK, Performance analysis, TOPSIS method.

Jel Classification: G11, L25.

\footnotetext{
*Arş. Gör. Dr. Çağatay Orçun, Dokuz Eylül Üniversitesi, İ̈BF, cagatay.orcun@deu.edu.tr

${ }^{* *}$ Arş. Gör. B. Selman Eren, Dokuz Eylül Üniversitesi, İIBF, selman.eren@deu.edu.tr
} 


\section{GİRiş}

Ülkeler arasında ekonomik büyüme farklılıklarının oluşmasının en önemli etkenlerinden birisi, ülkelerin teknolojik yeteneklerini ne hızda geliştirebildikleri konusudur. $\mathrm{Bu}$ açıdan bakıldığında, teknoloji ve teknoloji ile iç içe olan sektörlerde faaliyet gösteren işletmelerin performansları önemli hale gelmektedir.

Teknoloji sektörü, bilgisayar yazılımı, donanımı, ağları, bilgi ve iletişim teknolojileri, internet, intranet gibi birçok farklı alana sahiptir. Çok dinamik bir yapıya sahip olmasından dolayı da bu alanda her geçen gün yeni gelişmeler ortaya çıkmaktadır. Dolayısıyla teknoloji sektörü, işletmelerin stratejilerini, karar alma yöntemlerini, karşılaş̧ıkları problemleri çözme yöntemlerini kolaylaştırmaktadır. Özellikle son yıllarda yaşanan hızlı teknolojik değişimler hayatın her alanında hissedilmeye başlamıştır. Gelişen teknoloji ile üretim şekilleri ve buna bağlı olarak diğer sektörler de değişmektedir. Gelişen teknolojiler bütün yaşamı etkilemekle birlikte, teknoloji sektöründe faaliyet gösteren işletmeler her geçen gün artmakta, sektör genişlemekte ve derinleşmektedir.

Ülkemizde de teknoloji sektöründe faaliyet gösteren işletmelerin sayısı günden güne artmaktadır. TÜBİSAD (Bilişim Sanayicileri Derneği) tarafından yapılan açıklamada, Türkiye Bilgi ve İletişim Teknolojileri sektörü hızlı bir büyüme göstermekle birlikte yaklaşık 70 milyar TL'lik büyüklüğe ulaşmıştır. TÜBİSAD Bilgi ve İletişim Teknolojileri sektörü verilerine göre 2015 yllında sektör \% 12,1'lik büyüme sağlamış, istihdam düzeyi 103 bin kişiye ulaşmış ve ihracattaki pay 1,34 milyar TL seviyesinde gerçekleşmiştir (TÜBİSAD, http://www.tubisad.org.tr, 2014). Sektörün hızlı gelişimi, sektör içinde faaliyet göstermekte olan işletmelerin mali performanslarının değerlendirilmesini önemli hale getirmiştir.

$\mathrm{Bu}$ kapsamda çalışma, giriş, yazın taraması, metodoloji ile araştırmanın bulgu ve sonuçlarının yorumlanması olmak üzere dört bölümden meydana gelmektedir. Çalışmaya 2010-2015 yılları arasında Borsa İstanbul (BIST) teknoloji sektöründe faaliyet gösteren 13 şirket dahil edilmiş ve bu yıllar arasındaki şirketlerin finansal tabloları esas alınarak oran analizleri yapılmıştır. $\mathrm{Bu}$ oran analizlerinden elde edilen veriler, TOPSIS yöntemi ile değerlendirilmiş ve şirketlerin performans düzeyleri karşılaştırılmıştır.

\section{YAZIN TARAMASI}

TOPSIS yöntemi ile ilgili yazın incelendiğinde, yöntemin belirli kriterler doğrultusunda finansal performansın değerlendirilmesi amacıyla kullanıldığı görülmektedir.

Feng ve Wang'ın (2000) çalışmasında Tayvan'da faaliyet gösteren beş havayolu işletmesinin performansını TOPSIS yöntemini kullanarak analiz edilmiştir. Çalışmada Tayvan havayolu işletmelerinin ulaştırma ve finansal göstergeleri olarak 22 değişken ele alınmış ve bu işletmelerin performansları bu değişkenler doğrultusunda sıralanmıştır. Çalışmada doğru finansal oranların belirlenmesinin, performans hesaplamada son derece önemli olduğu sonucuna ulaşılmıştır. 
Feng ve Wang'ın (2001) başka bir çalışmasında TOPSIS yöntemi kullanılarak dört otobüs şirketinin üretim faaliyetlerine, pazarlama çabalarına ve finansal göstergelerine ait oranları dikkate alınarak performansları analiz edilmiştir ve şirketler sıralandırılmıştır.

Yurdakul ve İç (2003) Türkiye'de Otomotiv sanayinde faaliyet gösteren beş büyük ölçekli firmanın 1998-2001 yılları arasındaki bilançolarını kullanarak, finansal oranlar (cari oran, stok devir hızı, kısa vadeli borçlar/toplam borç, brüt satış karı/net satışlar, esas faaliyet karı/net satışlar oranları) yardımıyla firmaları derecelendirmişlerdir. Çalışmanın birinci bölümünde performans ölçümünde kullanılan finansal oranlar açıklanmış ve firmalar için hesaplanmıştır. İkinci bölümde ise, hesaplanan oranlar her firma için TOPSIS yöntemi ile genel firma performansını gösteren tek bir puana çevrilmiştir. Çalışma sonucunda, TOPSIS yöntemi sonucu oluşturulan performans sıralamaları ile firmaların hisse senedi getiri sıralamaları arasında benzerlikler tespit edilmiştir.

Akkaya (2004) tarafından Türkiye'de faaliyet gösteren bir havayolu işletmesinin performansı TOPSIS yöntemi kullanılarak analiz edilmiştir. Çalışmada, 63 rasyo üretim, pazarlama ve faaliyet göstergeleri olarak sınıflandırılmışıtır. İşletmenin performansının değerlendirilmesinde 13 rasyo kullanılmıştır. Çalışmanın sonucu olarak geliştirilen yöntem ve elde edilen sonuçların, havayolu işletmeleri için performans değerlendirmede bir yol haritası olacağı belirtilmiştir.

Wang ve Hsu (2004) tarafindan Tayvan menkul kıymetler borsasında işlem gören 10 işletme üzerinde 4 adet finansal oran kullanarak (stok devir hızı, net kar marjı, hisse başına getiri ve cari oran) yapılan çalışmada TOPSIS yönteminin yatırımcıların kararlarında ve yatırım stratejilerini belirlenmesinde faydalı olabileceği belirtilmiştir.

Bo ve Haidong (2008) tarafindan Çin borsasında işlem gören 112 işletme üzerinde 11 adet finansal oran (Likidite oranı, asit test oranı, borçlanma oranı, çalışma sermayesi oranı, sermaye karlılığı, aktif karlılığı, alacak, stok ve aktif devir hızı, net akış oranı net akış/cari yükümlülükler oranı) kullanılarak yapılan çalışmada TOPSIS yönteminin finansal kriz dönemlerinde işletmelerde erken uyarı sistemi olarak kullanılabileceği tespit edilmiştir.

Demireli (2010) tarafından Türkiye'de hizmet veren kamu sermayeli üç bankanın 2001-2007 yılları arasındaki 7 yıllık dönemde performansları TOPSIS performans değerleme sistemi ile analiz edilmiştir. Çalışmada TOPSIS puanlarının belirlenmesi amacıyla, Özsermaye/Toplam Aktifler, Toplam Krediler/Toplam Aktifler, Takipteki Krediler (Net)/ Toplam Krediler, Duran Aktifler/ Toplam Aktifler, Likit Aktifler/Toplam Aktifler, Likit Aktifler/Kısa Vadeli Yükümlülükler, Dönem Net Karı (Zararı)/ Toplam Aktifler, Dönem Net Karı(Zararı)/Özkaynaklar, Net Faiz Geliri/Toplam Aktifler, Net Faiz Geliri/Toplam Faaliyet Gelirleri oranları kullanılmıştır. Çalışmanın sonucunda, Türkiye'de yaygın olarak faaliyet gösteren kamu sermayeli bankaların yerel ve küresel finansal krizlerden etkilendiği, performans puanlarının yurtdışı verilere dayalı olarak dalgalanmalar gösterdiği, bankacılık sektöründe göze çarpan bir iyileşmenin yaşanmadığı tespit edilmiştir. 
Yükçü ve Atağan (2010) tarafindan bir holdinge bağlı aynı sektörde faaliyet gösteren üç otel işletmesi için performans hesaplaması gerçekleştirilmiştir. Çalışmada TOPSIS yönetiminin performans değerlendirmede başarılı sonuçlar verdiği ve karar vericilere bu yöntemin farklı değerlendirme seçenekleri sunduğu belirtilmiştir.

Wang, Chang, Anh ve Chang (2010) tarafindan yapılan çalışmada Vietnam borsasında işlem gören 13 işletmeye ait 6 adet finansal oran (varlık karlılığı, sermaye karlılığı, cari oran, hisse başına getiri, net kar marjı oranı ve stok devir hızı) kullanılarak gerçekleştirilen analiz sonucunda, TOPSIS yönteminin işletmelerin finansal performansının değerlendirilmesi ve yatırımcıların portföy oluşturmasında yararlı olabileceği ifade edilmiştir.

Torlak vd. (2011) Türkiye ulusal havayolu sektöründe faaliyet gösteren dört havayolu şirketine ait verimlilik, reklam, müşteri hizmetleri, ürün kalitesi, e-ticaret gibi verileri kullanarak bulanık TOPSIS yöntemiyle şirketlerin performanslarını değerlendirmişlerdir. Çalışmanın sonucunda, tüm başarı faktörleri ele alındığında, Türk Hava Yolları en başarılı şirket olarak belirlenirken, onu sırasıyla, Pegasus, Atlas Jet ve Onur Air izlemiştir.

Özgüven (2011) tarafından yapılan çalışmada, perakendecilik sektöründe faaliyet gösteren üç büyük hipermarketin performansı TOPSIS yöntemi ile analiz edilmiştir. Çalışmada 2005-2009 yılları arasında perakendecilerin performanslarını değerlendirmede kullanılan beş temel kriter dikkate alınmıştır. Bu kriterler; toplam mağaza sayısı/nüfus, çalışan sayısı/nüfus, yeni açılan mağaza sayısı/toplam mağaza sayısı, pazarlama satış ve dağıtım giderleri/toplam giderler ve net kar/net satışlar olarak belirlenmiştir. 2005-2009 yılları arasında perakendecilerin performansları değerlendirildiğinde 2005 ve 2006 yılı için Carrefour'un, 2007 ve 2008 yıllarında Migros'un, 2009 yılında ise Tesco-Kipa'nın performans açısından ilk sırada yer aldığı görülmektedir.

Kim ve Jung (2011) tarafından Kore borsasında işlem gören 8 işletme üzerinde 16 adet finansal kriter ile faktör analizi yaparak TOPSIS yöntemi sonuçları ve finansal oranların sonuçları arasında korelasyon analizi yapılmış ve ilişkinin düşük çıktığı görülmüştür. TOPSİS yönteminin yatırım alternatiflerinin seçiminde yeterli bir yöntem olduğu belirtilmiştir.

Atmaca (2012) İMKB'de işlem gören spor şirketlerinin finansal performansını TOPSIS yöntemini kullanarak değerlendirmiştir. Çalışmada Fenerbahçe (FB), Galatasaray (GS), Beşiktaş (BJK) ve Trabzonspor (TS) Sportif A.Ş.'nin 2003-2010 yılları arasında temel finansal tabloları (bilanço ve gelir tablosu) esas alınmıştır. Bu tablolardan yararlanılarak spor şirketlerinin varlık, sermaye, likidite, faaliyet, mali yapı ve karlılık düzeylerini gösteren toplam 16 finansal oran kullanılmıştır. Çalışmaya dahil edilen dört spor şirketinin başarılarının veya başarısızlıklarının finansal performans düzeyinde önemli rol oynadığı ve bu durumun şirketlerin finansal tablolarına yansıdığ 1 tespit edilmiştir.

Uygurtürk ve Korkmaz (2012), çalışmalarında IMKK' işlem gören 13 metal ana sanayi işletmesini, 2006-2010 dönemine ait mali tabloları kullanılarak, işletmelerin finansal performansları TOPSIS yöntemi ile analiz etmişlerdir. Öncelikle işletmelerin finansal yapısını 
ortaya koymak amaciyla finansal oranlar hesaplanmış, daha sonra hesaplanan oranlar; TOPSIS yöntemi kullanılarak genel şirket performansını gösteren tek bir puana çevrilmiştir. Çalışmada; Cari Oran, Likidite Oranı, Stok Devir Hızı, Sabit Aktif Devir Hızı, Toplam Aktif Devir Hızı, Toplam Borçlar/Toplam Aktifler, Net Kar Marjı ve Öz Sermaye Karlılı̆̆ı olarak 8 adet finansal oran kullanılmıştır. Hesaplanan finansal oranlar TOPSIS yönteminin girdisi olarak kullanılmış ve buna bağlı olarak işletmelerin performans sıralaması gerçekleştirilmiştir. Dolayısıyla benzeri işletmelerin aynı kriterler çerçevesinde karşılaştırılarak rakamsal olarak başarılarının belirlenmesi ve sıralamalarının yapılması gerçekleştirilmiştir. Son olarak ise TOPSIS yönteminin belirlediği performans sırası yüksek ve düşük işletmelerden oluşan iki portföy oluşturulmuş ve bu portföylerin getirileri TOPSIS yönteminin performans siralaması arasındaki ilişki belirlenmeye çalışılmıştır.

\section{ARAȘTIRMANIN AMACI VE KAPSAMI}

Araştırmanın temel amacı, Borsa İstanbul A.Ş. Teknoloji endeksinde (XUTEK) yer alan şirketlerin finansal performanslarının TOPSIS yöntemi ile değerlendirilmesi ve birbirleriyle karşılaştırılmasıdır. Buna ek olarak, şirketlerin finansal performans sıralamaları ile borsa getirisi sıralamalarının birbiriyle ilişkili olup olmadıklarının incelenmesi de amaçlanmaktadir.

Çalışmaya, 2010-2015 yıllarını kapsayacak şekilde, hisse senetleri borsada işlem gören 13 şirket dâhil edilmiştir. Analiz kapsamında yer alan şirketler Tablo 1'de gösterilmektedir.

Tablo 1. Analiz Kapsamında Yer Alan Şirketler

\begin{tabular}{|c|c|c|}
\hline \multicolumn{1}{|c|}{ Şirket } & Kodu \\
\hline $\mathbf{1}$ & Alcatel Lucent Teletaş Telekomünikasyon A. Ş. & ALCTL \\
\hline $\mathbf{2}$ & Anel Telekomünikasyon Elektronik. Sis. San. Tic. A. Ş. & ANELT \\
\hline $\mathbf{3}$ & Arena Bilgisayar San. Tic. A. Ş. & ARENA \\
\hline $\mathbf{4}$ & Armada Bilgisayar Sistemleri San. Tic. A. Ş. & ARMDA \\
\hline $\mathbf{5}$ & Aselsan Elektronik San. Tic. A. Ş. & ASELS \\
\hline $\mathbf{6}$ & Datagate Bilgisayar Malzemeleri Tic. A. Ş. & DGATE \\
\hline $\mathbf{7}$ & Escort Teknoloji Yatırım A. Ş. & ESCOM \\
\hline $\mathbf{8}$ & İndeks Bilgisayar Sis. Müh. San. Tic. A. Ş. & LINK \\
\hline $\mathbf{9}$ & Karel Elektronik San. Tic. A.Ş. \\
\hline $\mathbf{1 0}$ & Link Bilgisayar Sis. Yazılım ve Donanım San. Tic. A. Ş. & KAREL \\
\hline
\end{tabular}




\begin{tabular}{|c|c|c|}
\hline 11 & Logo Yazılım San. Tic. A. Ş. & LOGO \\
\hline $\mathbf{1 2}$ & Netaş Telekomünikasyon A. Ş. & NETAS \\
\hline $\mathbf{1 3}$ & Plastikkart Akıllı Kart İletişim Sis. San. Tic. A. Ş. & PKART \\
\hline
\end{tabular}

\section{ARAŞTIRMANIN VERILERİ VE YÖNTEMI}

Araştırmanın konusunu oluşturan şirketlerin finansal performansları, TOPSIS yöntemi kullanılarak belirlenmeye çalışılmış ve modelin çözümünde Microsoft Office Excel paket programından yararlanılmıştır. Yılsonu verilerinin kullanıldığı analizde, veriler Kamuyu Aydınlatma Platformu internet sitesinde yer alan şirketlerin bilançolarından elde edilerek hazırlanmıştır.

Çalışmada kullanılan ve Tablo 2'de yer alan finansal oranlar, şirketlerin borç ödeme güçleri, finansal yapıları, karlılıkları ve varlıklarının etkin kullanımı hakkında bilgi verebilecek nitelikteki oranlar arasından seçilmiştir.

Tablo 2. Çalışmada Kullanılan Finansal Oranlar

\begin{tabular}{|c|c|c|}
\hline I1 & Cari Oran & Dönen Varlıklar / KVYK \\
\hline $\mathbf{I 2}$ & Asit-Test Oranı & (Dönen Varlıklar-Stoklar) / KVYK \\
\hline I3 & Hazine Oranı & (Dönen Varlıklar-Stoklar-Alacaklar) / KVYK \\
\hline I4 & Kaldıraç Oranı & Toplam Borç / Toplam Aktif \\
\hline $\mathbf{I 5}$ & Aktif Devir Hızı Oranı & Net Satışlar / Toplam Aktif \\
\hline I6 & Özsermaye Devir Hızı Oranı & Net Satışlar / Özsermaye \\
\hline $\mathbf{I 7}$ & Satış Karlılı̆ğ & Net Kar / Net Satışlar \\
\hline I8 & Özsermaye Karlılığ1 & Net Kar / Özsermaye \\
\hline $\mathbf{I 9}$ & Esas Faaliyet Karlılı̆̆ & Net Kar / Esas Faaliyet Karı \\
\hline
\end{tabular}

Çalışmada seçilen oranlardan cari, asit-test ve hazine oranı, şirketlerin varlık kalemlerinin kısa vadeli yükümlülüklerini yerine getirebilme güçlerini ölçmede (likidite analizi); kaldıraç oranı, finans yönetiminin temel amaçlarından birisi olan "uygun finansal yapının oluşturulması" amacı doğrultusunda şirketlerinin finansal yapılarının oransal dağılımlarının belirlenmesinde; aktif ve özsermaye devir hızı oranları, ilgili kalemlerin etkin kullanımlarının belirlenmesinde ve karlılık oranları ise, şirketlerin karlılıklarının ölçülmesi kapsamında kullanılmıştır.

Yazın taraması sonucunda finansal performansların değerlendirilmesinde kullanılan göstergelerin, hesaplamalarda kullanılacak ağırlıklarının çalışmadan çalışmaya farklılaştığı gözlemlenmiştir. Bu kapsamda, performans kriterlerine ilişkin çalışmada kullanılan ağırlıklar 
şu şekildedir; I1: 0,09, I2: 0,08, I3: 0,08, I4: 0,25, I5: 0,13, I6: 0,12, I7: 0,09, I8: 0,08 ve I9: $0,08 . \mathrm{Bu}$ ağırlıkların belirlenmesinde, finans bilim alanı öğretim üyelerinin görüşlerinden yararlanılmıştır(Akkaya,2004:15-29 ve Demireli,2010:101-112).

TOPSIS (Technique for Order Preference by Similarity to Ideal Solution) yöntemi Yoon ve Hwang (1981) tarafından çok kriterli karar verme tekniği olarak geliştirilmiştir. TOPSIS kavramı, en çok tercih edilen alternatifin, sadece pozitif ideal çözüme en yakın uzaklıkta olan değil aynı zamanda negatif ideal çözüme en uzak alternatifin olduğuna dayanan bir tekniktir (Atmaca, 2012: 96). Aşağıda 6 temel adımdan oluşan TOPSIS yönteminin performans değerleme süreci yer almaktadır (Dumanoğlu ve Ergül, 2010: 105-107).

\section{Adım 1. Karar Matrisinin (A) Oluşturulması}

Karar matrisinin satırlarında üstünlükleri sıralanmak istenen karar noktaları, sütunlarında ise karar vermede kullanılacak değerlendirme faktörleri yer alır. A matrisi karar verici tarafından oluşturulan başlangıç matrisidir. Karar matrisi aşağıdaki gibi gösterilir:

$$
A_{i j}=\left[\begin{array}{cccc}
a_{11} & a_{12} & \ldots & a_{1 n} \\
a_{21} & a_{22} & \ldots & a_{2 n} \\
\cdot & & & \cdot \\
\cdot & & & \cdot \\
\cdot & & & \cdot \\
a_{m 1} & a_{m 2} & \ldots & a_{m n}
\end{array}\right]
$$

$A_{i j}$ matrisinde m karar noktası sayısını, n değerlendirme faktörü sayısını verir.

\section{Adım 2. Standart Karar Matrisinin (R) Oluşturulması}

Standart Karar Matrisi, A matrisinin elemanlarından yararlanarak ve aşağıdaki formül kullanılarak hesaplanır.

$$
r_{i j}=\frac{a_{i j}}{\sqrt{\sum_{k=1}^{m} a_{k j}^{2}}}
$$

$\mathrm{R}$ matrisi aşağıdaki gibi elde edilir:

$$
R_{i j}=\left[\begin{array}{cccc}
r_{11} & r_{12} & \ldots & r_{1 n} \\
r_{21} & r_{22} & \ldots & r_{2 n} \\
\cdot & & & \cdot \\
\cdot & & & \cdot \\
\cdot & & & \cdot \\
r_{m 1} & r_{m 2} & \ldots & r_{m n}
\end{array}\right]
$$




\section{Adım 3. Ağırlıklı Standart Karar Matrisinin (V) Oluşturulması}

Öncelikle değerlendirme faktörlerine ilişkin ağırlık değerleri $\left(\mathrm{w}_{\mathrm{i}}\right)$ belirlenir. Daha sonra R matrisinin her bir sütunundaki elemanlar ilgili $\mathrm{w}_{\mathrm{i}}$ değeri ile çarpılarak $\mathrm{V}$ matrisi oluşturulur. V matrisi aşağıda gösterilmiştir:

$$
V_{i j}=\left[\begin{array}{cccc}
w_{1} r_{11} & w_{2} r_{12} & \ldots & w_{n} r_{1 n} \\
w_{1} r_{21} & w_{2} r_{22} & \ldots & w_{n} r_{2 n} \\
\cdot & & & \cdot \\
\cdot & & & \cdot \\
\cdot & & & \cdot \\
w_{1} r_{m 1} & w_{2} r_{m 2} & \ldots & w_{n} r_{m n}
\end{array}\right]
$$

\section{Adım 4. İdeal $\left(\mathrm{A}^{+}\right)$ve Negatif İdeal (A) Çözümlerin Oluşturulması}

TOPSIS yöntemi, her bir değerlendirme faktörünün monoton artan veya azalan bir eğilime sahip olduğunu varsaymaktadır.

İdeal çözüm setinin oluşturulabilmesi için $\mathrm{V}$ matrisindeki ağırlıklandırılmış değerlendirme faktörlerinin yani sütun değerlerinin en büyükleri (ilgili değerlendirme faktörü minimizasyon yönlü ise en küçüğü) seçilir. İdeal çözüm setinin bulunması aşağıdaki formülde gösterilmiştir.

$$
A^{*}=\left\{\left(\max _{i} v_{i j} \mid j \in J\right),\left(\min _{i} v_{i j} \mid j \in J^{\prime}\right\}\right.
$$

(5) formülünden hesaplanacak set $A^{*}=\left\{v_{1}^{*}, v_{2}^{*}, \ldots, v_{n}^{*}\right\}$ şeklinde gösterilebilir.

Negatif ideal çözüm seti ise, V matrisindeki ağırlıklandırılmış değerlendirme faktörlerinin yani sütun değerlerinin en küçükleri (ilgili değerlendirme faktörü maksimizasyon yönlü ise en büyüğ̈̈) seçilerek oluşturulur. Negatif ideal çözüm setinin bulunması aşağıdaki formülde gösterilmiştir.

$$
A^{-}=\left\{\left(\min _{i} v_{i j} \mid j \in J\right),\left(\max _{i} v_{i j} \mid j \in J^{\prime}\right\}\right.
$$

(6) formülünden hesaplanacak set $A^{-}=\left\{v_{1}^{-}, v_{2}^{-}, \ldots, v_{n}^{-}\right\}$şeklinde gösterilebilir.

Her iki formülde de $J$ fayda (maksimizasyon), $J^{\prime}$ ise kayıp (minimizasyon) değerini göstermektedir. Gerek ideal gerekse negatif ideal çözüm seti, değerlendirme faktörü sayısı yani m elemandan oluşmaktadır.

\section{Adım 5. Ayırım Ölçülerinin Hesaplanması}

TOPSIS yönteminde her bir karar noktasına ilişkin değerlendirme faktör değerinin ideal ve negatif ideal çözüm setinden sapmalarının bulunabilmesi için Euclidian Uzaklık Yaklaşımından yararlanılmaktadır. Buradan elde edilen karar noktalarına ilişkin sapma 
değerleri ise ideal ayırım $\left(S_{i}^{*}\right)$ ve negatif ideal ayırım $\left(S_{i}^{-}\right)$ölçüsü olarak adlandırılmaktadır. İdeal ayırım ( $\left.S_{i}^{*}\right)$ ölçüsünün hesaplanması (7) numaralı formülde, negatif ideal ayırım $\left(S_{i}^{-}\right)$ ölçüsünün hesaplanması ise (8) numaralı formülde gösterilmiştir.

$$
\begin{aligned}
& S_{i}^{*}=\sqrt{\sum_{j=1}^{n}\left(v_{i j}-v_{j}^{*}\right)^{2}} \\
& S_{i}^{-}=\sqrt{\sum_{j=1}^{n}\left(v_{i j}-v_{j}^{-}\right)^{2}}
\end{aligned}
$$

Burada hesaplanacak $S_{i}^{*}$ ve $S_{i}^{-}$sayısı doğal olarak karar noktası sayısı kadar olacaktır.

\section{Adım 6. İdeal Çözüme Göreli Yakınlığın Hesaplanması}

Her bir karar noktasının ideal çözüme göreli yakınlığının $\left(C_{i}^{*}\right)$ hesaplanmasında ideal ve negatif ideal ayırım ölçülerinden yararlanılır. Burada kullanılan ölçüt, negatif ideal ayırım ölçüsünün toplam ayırım ölçüsü içindeki payıdır. İdeal çözüme göreli yakınlık değerinin hesaplanması aşağıdaki formülde gösterilmiştir.

$$
C_{i}^{*}=\frac{S_{i}^{-}}{S_{i}^{-}+S_{i}^{*}}
$$

Burada $C_{i}^{*}$ değeri $0 \leq C_{i}^{*} \leq 1$ aralı̆ı̆nda değer alır ve $C_{i}^{*}=1$ ilgili karar noktasının ideal çözüme, $C_{i}^{*}=0$ ilgili karar noktasının negatif ideal çözüme mutlak yakınlığını gösterir. Elde edilen değerler, büyüklük sırasına göre dizilerek karar noktalarının önem sıraları belirlenir.

\section{BULGULAR VE DEĞERLENDİRILMESI}

Çalışmanın bu bölümünde analiz kapsamına alınan 13 şirketin TOPSIS yöntemi kullanılarak 2010-2015 yıllarına ilişkin performansları belirlenmiştir. Örnek teşkil etmesi açısından TOPSIS yönteminin aşamaları 2010 yılı için aşağıdaki gibidir.

\section{Adım 1: Karar Matrisinin Oluşturulması}

TOPSIS yönteminin ilk adımı olan karar matrisi, teknoloji şirketleri için Tablo 3'teki gibi oluşturulmuştur. 
Tablo 3. 2010 Y1lı Karar Matrisi (A)

\begin{tabular}{|c|cccccccccc|c|}
\hline 2010 & I1 & I2 & I3 & I4 & I5 & I6 & I7 & I8 & I9 \\
\hline ALCTL & 1,32 & 1,13 & 0,28 & 0,74 & 1,26 & 4,87 & 0 & 0,01 & 0 \\
\hline ANELT & 1,02 & 0,92 & 0,26 & 0,83 & 0,48 & 2,77 & $-0,12$ & $-0,33$ & $-0,08$ \\
\hline ARENA & 1,5 & 0,89 & 0,11 & 0,65 & 3,63 & 10,3 & 0,02 & 0,21 & 0,04 \\
\hline ARMDA & 1,3 & 0,99 & 0,14 & 0,76 & 2,33 & 9,81 & 0,02 & 0,19 & 0,03 \\
\hline ASELS & 3,04 & 2,06 & 1,78 & 0,61 & 0,53 & 1,37 & 0,19 & 0,26 & 0,15 \\
\hline DGATE & 1,39 & 1,02 & 0,25 & 0,72 & 3,74 & 13,23 & 0,01 & 0,07 & 0,02 \\
\hline ESCOM & 0,86 & 0,67 & 0,12 & 0,74 & 0,69 & 2,67 & 0,01 & 0,04 & 0,29 \\
\hline INDES & 1,24 & 0,93 & 0,16 & 0,78 & 2,28 & 10,2 & 0,01 & 0,12 & 0,31 \\
\hline KAREL & 1,99 & 1,63 & 1,08 & 0,56 & 0,53 & 1,21 & 0,14 & 0,17 & 1,01 \\
\hline LINK & 2,15 & 11,92 & 1,16 & 0,14 & 0,51 & 0,59 & $-0,13$ & $-0,08$ & 0,73 \\
\hline LOGO & 2,54 & 2,5 & 1,12 & 0,16 & 0,56 & 0,66 & $-0,02$ & $-0,01$ & 0,75 \\
\hline NETAS & 2,44 & 2,25 & 1,17 & 0,27 & 0,67 & 0,92 & 0,09 & 0,08 & 1,21 \\
\hline PKART & 8,9 & 5,71 & 8,41 & 0,16 & 1,3 & 1,54 & 0,01 & 0,01 & -1 \\
\hline
\end{tabular}

\section{Adım 2. Standart Karar Matrisinin Olușturulması}

Karar matrisinde yer alan ilgili sütun değerlerinin kareleri toplamının kareköküne bölünmesiyle karar matrisi standart hale getirilmektedir (Tablo 4).

Tablo 4. 2010 Y1lı Standart Karar Matrisi (R)

\begin{tabular}{|cccccccc|c|c|c|c|}
\hline 2010 & I1 & I2 & \multicolumn{1}{c}{ I3 } & \multicolumn{1}{c}{ I4 } & I5 & I6 & I7 & I8 & I9 \\
\hline ALCTL & 0,120 & 0,080 & 0,031 & 0,340 & 0,191 & 0,212 & 0,000 & 0,018 & 0,000 \\
\hline ANELT & 0,093 & 0,065 & 0,029 & 0,381 & 0,073 & 0,121 & $-0,386$ & $-0,584$ & $-0,037$ \\
\hline ARENA & 0,137 & 0,063 & 0,012 & 0,299 & 0,551 & 0,449 & 0,064 & 0,371 & 0,018 \\
\hline ARMDA & 0,118 & 0,070 & 0,016 & 0,349 & 0,354 & 0,427 & 0,064 & 0,336 & 0,014 \\
\hline ASELS & 0,277 & 0,146 & 0,200 & 0,280 & 0,080 & 0,060 & 0,611 & 0,460 & 0,069 \\
\hline DGATE & 0,127 & 0,072 & 0,028 & 0,331 & 0,568 & 0,576 & 0,032 & 0,124 & 0,009 \\
\hline ESCOM & 0,078 & 0,047 & 0,013 & 0,340 & 0,105 & 0,116 & 0,032 & 0,071 & 0,132 \\
\hline INDES & 0,113 & 0,066 & 0,018 & 0,358 & 0,346 & 0,444 & 0,032 & 0,212 & 0,142 \\
\hline KAREL & 0,181 & 0,116 & 0,121 & 0,257 & 0,080 & 0,053 & 0,450 & 0,301 & 0,461 \\
\hline LINK & 0,196 & 0,845 & 0,130 & 0,064 & 0,077 & 0,026 & $-0,418$ & $-0,142$ & 0,333 \\
\hline LOGO & 0,232 & 0,177 & 0,126 & 0,073 & 0,085 & 0,029 & $-0,064$ & $-0,018$ & 0,343 \\
\hline NETAS & 0,222 & 0,159 & 0,131 & 0,124 & 0,102 & 0,040 & 0,289 & 0,142 & 0,553 \\
\hline PKART & 0,811 & 0,405 & 0,944 & 0,073 & 0,197 & 0,067 & 0,032 & 0,018 & $-0,457$ \\
\hline
\end{tabular}




\section{Adım 3. Ağırlıklı Standart Karar Matrisinin Oluşturulması}

Performans kriterlerine atanmış olan ağırlık değerleri $\left(\mathrm{w}_{\mathrm{i}}\right)$, bir önceki adımda hesaplanan standart değerler ile çarpılarak ağırlıklı standart karar matrisi oluşturulmaktadır (Tablo 5).

Tablo 5. 2010 Y 1lı Ağırlıklı Standart Karar Matrisi (V)

\begin{tabular}{|c|c|c|c|c|c|c|c|c|c|c|}
\hline 2010 & I1 & I2 & I3 & I4 & I5 & I6 & I7 & I8 & I9 \\
\hline ALCTL & 0,011 & 0,006 & 0,003 & 0,085 & 0,025 & 0,025 & 0,000 & 0,001 & 0,000 \\
\hline ANELT & 0,008 & 0,005 & 0,002 & 0,095 & 0,009 & 0,014 & $-0,035$ & $-0,047$ & $-0,003$ \\
\hline ARENA & 0,012 & 0,005 & 0,001 & 0,075 & 0,072 & 0,054 & 0,006 & 0,030 & 0,001 \\
\hline ARMDA & 0,011 & 0,006 & 0,001 & 0,087 & 0,046 & 0,051 & 0,006 & 0,027 & 0,001 \\
\hline ASELS & 0,025 & 0,012 & 0,016 & 0,070 & 0,010 & 0,007 & 0,055 & 0,037 & 0,005 \\
\hline DGATE & 0,011 & 0,006 & 0,002 & 0,083 & 0,074 & 0,069 & 0,003 & 0,010 & 0,001 \\
\hline ESCOM & 0,007 & 0,004 & 0,001 & 0,085 & 0,014 & 0,014 & 0,003 & 0,006 & 0,011 \\
\hline INDES & 0,010 & 0,005 & 0,001 & 0,090 & 0,045 & 0,053 & 0,003 & 0,017 & 0,011 \\
\hline KAREL & 0,016 & 0,009 & 0,010 & 0,064 & 0,010 & 0,006 & 0,041 & 0,024 & 0,037 \\
\hline LINK & 0,018 & 0,068 & 0,010 & 0,016 & 0,010 & 0,003 & $-0,038$ & $-0,011$ & 0,027 \\
\hline LOGO & 0,021 & 0,014 & 0,010 & 0,018 & 0,011 & 0,003 & $-0,006$ & $-0,001$ & 0,027 \\
\hline NETAS & 0,020 & 0,013 & 0,011 & 0,031 & 0,013 & 0,005 & 0,026 & 0,011 & 0,044 \\
\hline PKART & 0,073 & 0,032 & 0,076 & 0,018 & 0,026 & 0,008 & 0,003 & 0,001 & $-0,037$ \\
\hline
\end{tabular}

\section{Adım 4. İdeal ( $\left.\mathrm{A}^{+}\right)$ve Negatif İdeal (A-) Çözümlerin Oluşturulması}

İdeal $\mathrm{A}^{+}$çözümünün belirlenmesi için $\mathrm{V}$ matrisinin her bir sütunundaki maksimum değer, İdeal $\mathrm{A}^{-}$çözümü için ise, $\mathrm{V}$ matrisinin her bir sütunundaki minimum değer seçilmektedir.

$$
\begin{aligned}
& \mathrm{A}^{+}=(0,073 ; 0,068 ; 0,076 ; 0,095 ; 0,074 ; 0,069 ; 0,055 ; 0,037 ; 0,044) \\
& \mathrm{A}^{-}=(0,007 ; 0,004 ; 0,001 ; 0,016 ; 0,009 ; 0,003 ;-0,038 ;-0,047 ;-0,037)
\end{aligned}
$$

\section{Adım 5. Ayırım Ölçülerinin Hesaplanması}

Her karar noktasının pozitif ideal çözümden olan mesafesi $\mathrm{S}^{+}$ve negatif ideal çözümden olan mesafesi $\mathrm{S}^{-}$aşağıdaki gibidir.

$$
\mathrm{S}^{+}=(0,1539 ; 0,1947 ; 0,1349 ; 0,1374 ; 0,1380 ; 0,1363 ; 0,1602 ; 0,1368 ; 0,1428 ;
$$
$0,1823 ; 0,1718 ; 0,1534 ; 0,1538)$

$S^{-}=(0,1034 ; 0,0871 ; 0,1387 ; 0,1327 ; 0,1449 ; 0,1392 ; 0,1077 ; 0,1317 ; 0,1386 ;$ $0,0978 ; 0,0874 ; 0,1211 ; 0,1226)$ 


\section{Adım 6. İdeal Çözüme Göreli Yakınlığın Hesaplanması}

Her bir karar noktasının ideal çözüme göreli yakınlığı $C_{i}$ (9) numaralı denklem yardımıyla hesaplanabilmektedir.

$$
\mathrm{C}=(0,4018 ; 0,3092 ; 0,5070 ; 0,4913 ; 0,5123 ; 0,5053 ; 0,4021 ; 0,4904 ; 0,4925 ;
$$

$0,3492 ; 0,3373 ; 0,4412 ; 0,4436)$

$\mathrm{Bu}$ adımlardan hareketle şirketlerin 2010-2015 yılına ilişkin performans değerleri ve sıralamaları Tablo 6'daki gibidir.

Tablo 6. Şirketlerin Performans Değerleri ve Sıralamaları

\begin{tabular}{|c|c|c|c|c|c|c|}
\hline & C (2010) & Sira & $\mathrm{C}(2011)$ & Sira & $\mathrm{C}(2012)$ & Sira \\
\hline ALCTL & 0,4018 & 10 & 0,3541 & 7 & 0,4931 & 4 \\
\hline ANELT & 0,3092 & 13 & 0,3234 & 9 & 0,3624 & 13 \\
\hline ARENA & 0,5070 & 2 & 0,4260 & 5 & 0,4974 & 3 \\
\hline ARMDA & 0,4913 & 5 & 0,4281 & 4 & 0,5109 & 1 \\
\hline ASELS & 0,5123 & 1 & 0,3340 & 8 & 0,4788 & 5 \\
\hline DGATE & 0,5053 & 3 & 0,4416 & 3 & 0,4569 & 7 \\
\hline ESCOM & 0,4021 & 9 & 0,3027 & 11 & 0,4045 & 12 \\
\hline INDES & 0,4904 & 6 & 0,4420 & 2 & 0,5016 & 2 \\
\hline KAREL & 0,4925 & 4 & 0,3121 & 10 & 0,4240 & 9 \\
\hline LINK & 0,3492 & 11 & 0,5952 & 1 & 0,4142 & 10 \\
\hline LOGO & 0,3373 & 12 & 0,2868 & 12 & 0,4702 & 6 \\
\hline NETAS & 0,4412 & 8 & 0,2794 & 13 & 0,4095 & 11 \\
\hline PKART & 0,4436 & 7 & 0,3676 & 6 & 0,4395 & 8 \\
\hline & $\mathrm{C}(2013)$ & Sura & $\mathrm{C}(2014)$ & Sira & $\mathrm{C}(2015)$ & Sira \\
\hline ALCTL & 0,3937 & 10 & 0,3789 & 6 & 0,4055 & 6 \\
\hline ANELT & 0,2549 & 13 & 0,3919 & 5 & 0,2926 & 12 \\
\hline ARENA & 0,4855 & 5 & 0,4102 & 4 & 0,4205 & 5 \\
\hline ARMDA & 0,4930 & 4 & 0,4230 & 3 & 0,4405 & 4 \\
\hline ASELS & 0,4405 & 7 & 0,3126 & 13 & 0,3474 & 11 \\
\hline DGATE & 0,4064 & 8 & 0,4433 & 2 & 0,5018 & 1 \\
\hline ESCOM & 0,3905 & 12 & 0,3438 & 9 & 0,2610 & 13 \\
\hline INDES & 0,4940 & 3 & 0,4508 & 1 & 0,4933 & 2 \\
\hline KAREL & 0,4008 & 9 & 0,3147 & 12 & 0,3507 & 10 \\
\hline LINK & 0,5868 & 1 & 0,3785 & 7 & 0,4662 & 3 \\
\hline LOGO & 0,4968 & 2 & 0,3641 & 8 & 0,3612 & 9 \\
\hline NETAS & 0,3919 & 11 & 0,3352 & 10 & 0,3785 & 7 \\
\hline PKART & 0,4483 & 6 & 0,3323 & 11 & 0,3784 & 8 \\
\hline
\end{tabular}


Tablo 6'ya göre, teknoloji sektöründe yer alan şirketlerin finansal performansları farklılıklar göstermektedir. Yıllar itibariyle en iyi finansal performansa sahip şirketler sırasıyla, ASELS, LINK, ARMDA, LINK, INDES ve DGATE şeklindedir. 6 yıllık süreç ele alındığında ise, göreceli olarak en yüksek performansa sahip şirket, INDES olarak görülmektedir.

Diğer çalışmalardan farklı olarak teknoloji sektöründe yer alan şirketlerin finansal performansları ile yıllık getirileri karşılaştırılmış, bu iki değişken arasında anlamlı bir ilişkinin var olup olmadığ da araştırılmıştır. Tablo 7'de şirketlerin yıllık kapanış fiyatları üzerinden hesaplanan getiri siralamaları yer almaktadır.

Tablo 7. Şirketlerin Getiri Siralamaları

\begin{tabular}{|c|c|c|c|c|c|c|}
\hline & 2010 & 2011 & 2012 & 2013 & 2014 & 2015 \\
\hline ALCTL & 10 & 4 & 5 & 9 & 11 & 1 \\
\hline ANELT & 12 & 11 & 3 & 1 & 13 & 11 \\
\hline ARENA & 8 & 5 & 8 & 7 & 5 & 2 \\
\hline ARMDA & 3 & 13 & 4 & 6 & 3 & 3 \\
\hline ASELS & 13 & 3 & 7 & 4 & 8 & 6 \\
\hline DGATE & 4 & 12 & 6 & 8 & 2 & 2 \\
\hline$\overline{\text { ESCOM }}$ & 1 & $\overline{1}$ & 13 & 13 & 6 & 13 \\
\hline INDES & 5 & 8 & 2 & 5 & 7 & 10 \\
\hline KAREL & 7 & 7 & 12 & 10 & 12 & 8 \\
\hline LINK & 2 & 9 & 11 & 11 & 4 & 9 \\
\hline LOGO & 9 & 10 & 1 & 2 & 1 & 5 \\
\hline NETAS & 6 & 2 & 10 & 12 & 9 & 4 \\
\hline PKART & 11 & 6 & 9 & 3 & 10 & 7 \\
\hline
\end{tabular}

Tablo 7 incelendiğinde, yatırımcısına en yüksek sermaye kazancını sağlayan şirketler yıllar itibariyle, ESCOM, ESCOM, LOGO, ANELT, LOGO ve ALCTL şeklindedir.

Şirketlerin finansal performansları (FP) ile getirileri (G) arasındaki ilişki, SPSS 20 paket programında Spearman sıra korelasyonu ile incelenmiş ve sonuçları Tablo 8'de yer almaktadır. Şirket getirilerinin hesaplanmasında, ilgili dönemlere ait günlük kapanış fiyatlarından yararlanılmıştır. İlgili veriler, www.isyatirim.com.tr internet adresinden temin edilmiştir. 
Tablo 8. Spearman Sira Korelasyonu Bulguları

\begin{tabular}{|c|c|c|c|c|c|c|}
\hline & $\begin{array}{l}\text { FP-G } \\
(2010)\end{array}$ & $\begin{array}{l}\text { FP-G } \\
(2011)\end{array}$ & $\begin{array}{l}\text { FP-G } \\
(2012)\end{array}$ & $\begin{array}{l}\text { FP-G } \\
(2013)\end{array}$ & $\begin{array}{l}\text { FP-G } \\
(2014)\end{array}$ & $\begin{array}{l}\text { FP-G } \\
\text { (2015) }\end{array}$ \\
\hline Correlation Coefficient &,- 016 &,- 467 & ,511 & ,236 & ,396 & ,468 \\
\hline Sig. (2-tailed) & ,957 & ,108 &, 074 & ,437 &, 181 & ,107 \\
\hline $\mathbf{N}$ & 13 & 13 & 13 & 13 & 13 & 13 \\
\hline
\end{tabular}

Tablo 8'e göre, şirketlerin TOPSIS yöntemine göre belirlenen finansal performans sıralamaları ile getiri sıralamaları arasında anlamlı bir ilişki tespit edilememiştir. Bu durum, yatırımcıların Borsa İstanbul'da tasarruflarını değerlendirirken, şirketlerin finansal performanslarını dikkate almadıkları sonucunu ortaya koymaktadır.

\section{SONUÇ}

Teknolojinin, ülkelerin rekabet gücünün arttırılması ve refah düzeyinin yükseltilmesi bakımından taşıdığı önemin günden güne artışı, bu sektörde yer alan şirketlerin de daha stratejik bir konuma sahip olmasına sebebiyet vermektedir. $\mathrm{Bu}$ kapsamda şirketlerin gösterecekleri finansal performans, hem kendi yaşam süreleri hem de ülke ekonomisi açısından önem arz etmektedir.

Borsa İstanbul'da işlem gören teknoloji şirketlerinin TOPSIS yöntemi ile finansal performanslarının analiz edildiği bu çalışmada, 2010-2015 yılları arasında performans açısından en başarılı şirketler sırasıyla, ASELS, LINK, ARMDA, LINK, INDES ve DGATE şeklinde gerçekleşmiştir. Söz konusu sonuç, ASELS şirketinin özellikle kamuya yönelik yatırım alanlarına ve ülkenin savunma sanayisine yönelik çalışmalarda bulunması ile açıklanabilir. Öte yandan finansal performans açısından ilk sırada bulunan ASELS şirketinin diğer teknoloji yatırımında bulunan şirketlere de katkı verdiği bu anlamda özellikle faaliyet karlılığını ve likiditesini artırdığı da söylenebilir. Çalışma sonucunda teknoloji yatırımlarının büyük ölçekli yatırımlar olması nedeniyle söz konusu performans sıralamasında şirketlerin likiditelerinin, finansal yapı içerisinde özellikle uzun vadeli yatırımları finanse edecek devamlı sermaye büyüklügünün ve kapasite göstergesi olarak da duran varlık yatırımlarının ön plana çıktığı sonucuna da ulaşılmıştır.

Şirketlerin finansal performansları ile borsa getirileri arasında anlamlı bir ilişkinin var olup olmadığının belirlenmesine yönelik olarak gerçekleştirilen Spearman sıra korelasyonu sonucuna göre ise, şirketlerin finansal performansları ile borsa getirileri arasında anlamlı bir ilişki tespit edilememiştir. Bu durum özellikle Borsa İstanbul A.Ş. yatırımcılarının finansal göstergeleri dikkate alarak yatırım yapmak yerine gelen haberlere dayalı olarak yatırımlarını şekillendirdiği, bu durum da özellikle teknoloji sektöründe gelen haberlere göre pozisyon almanın piyasa etkinliğinden uzaklaşılmasına neden olduğu şeklinde yorumlanabilir. Yatırımcıların hisse alımlarını gerçekleştirirken gelen bilgiler yerine firmaların bilanço ve 
gelir tablolarından elde edilecek sonuçlara göre karar vermeleri hem borsayı etkinliğe yaklaştıracak, hem de borsanın kar firsatlarından daha doğru ve isabetli şekilde yararlanılarak uzun vadeli bir yatırım alternatifi şeklinde yorumlanmasını sağlayacaktır.

\section{KAYNAKLAR}

Akkaya, G. Cenk (2004), "Finansal Rasyolar Yardımıyla Havayolları İşletmelerinin Performansının Değerlendirilmesi”, Dokuz Eylül Üniversitesi İktisadi ve İdari Bilimler Fakültesi Dergisi, Say1: 19(1), ss. 15-29.

Atmaca, Metin (2012), “IMKB’de İşlem Gören Spor Şirketlerinin TOPSIS Yöntemi İle Finansal Performans Değerlendirmesi”, İktisat, İşletme ve Finans Dergisi, Sayı: 27(320), ss. 91-108.

Bo, Jin - Haidong, Li (2008), "Research on Financial Early Warning for Listed CompaniesBased on TOPSIS Method", http://www.seiofbluemountain.com/upload/product/200911/2008jrhy07a17.pdf (02.11.16).

Demireli, Erhan (2010), “TOPSİS Çok Kriterli Karar Verme Sistemi: Türkiye'deki Kamu Bankaları Üzerine Bir Uygulama”, Girişimcilik ve Kalkınma Dergisi, Sayı: 5(1), ss. 101-112.

Feng, C-Min - Wang, R-Tsu (2000), "Performance Evaluation For Airlines Including The Consideration of Financial Ratios", Journal of Air Transport Managemant, Sayı: 6, pp. 133-142.

Feng, C-Min - Wang, R-Tsu (2001), "Considering The Financial Ratios on The Performance Evaluation of Highway Industry”, Transport Reviews, Sayı: 21(4), pp. 449-467.

Kim, Gyutai - Jung, Suhee (2011), "Exploiting The Decision-Making Tecnique to Explore The Relationship Between The Financial Factors and The Stock Preference", http://ieomsociety.org/ieom2011/pdfs/IEOM067.pdf (02.11.16).

Özgüven, Nihan (2011), "Kriz Döneminde Küresel Perakendeci Aktörlerin Performanslarının TOPSIS Yöntemi İle Değerlendirilmesi”, Atatürk Üniversitesi İktisadi ve İdari Bilimler Fakültesi Dergisi, Sayı: 25(2), ss. 151-162.

Torlak, Gökhan - Şevkli, Mehmet - Sanal, Mehmet - Zaim, Selim (2011), "AnalyzingBusiness Competition By Using Fuzzy TOPSIS Method: An Example Of Turkish Domestic Airline Industry”, Expert Systems with Applications, Say1: 38, ss. 3396- 3406.

TÜBİSAD,(http://www.tubisad.org.tr/Tr/News/Sayfalar/tubisad_2014_pazar_verileri_bb.aspx , 2014). 
Uyguntürk, Hasan - Korkmaz, Turhan (2012), "Finansal Performansın TOPSIS Çok Kriterli Karar Verme Yöntemi İle Belirlenmesi: Ana Metal Sanayi İşletmeleri Üzerine Bir Uygulama”, Eskişehir Osmangazi Üniversitesi İ̈BF Dergisi, Sayı: 7(2), ss. 95-115.

Wang, T-Chin - Hsu, J-Chien (2004), "Evaluation of The Business Operation Performance of The Listing Companies by Applying TOPSIS Method", IEEE International Conference on Systems, Man and Cybernestics, Say1: 2, pp. 1286-1291.

Wang, T-Chin - Chang, J-Fang - Anh, T-Ngoc - Chang, T-Sang (2010), “Applying TOPSIS

Method to Evaluate The Business Operation Performance of Vietnam Listing Securities Companies", International Conference on Computational Aspects of Social Networks, IEEE Computer Society, pp. 273-277.

Yurdakul, Mustafa - İç, Yusuf Tansel (2003), “Türk Otomotiv Firmalarının Performans Ölçümü ve Analizine Yönelik Topsıs Yöntemini Kullanan Bir Örnek Çalışma”, Gazi Üniversitesi, Mühendislik ve Mimarlık Fakültesi Dergisi, Cilt 18, No 1, ss.1-18.

Yükçü, Süleyman - Atağan, Gülşah (2010), “TOPSIS Yöntemine Göre Performans Değerleme", Muhasebe ve Finansman Dergisi, Say1: 1(45), ss. 28-35. 